\title{
Indikasi vitrektomi pada kelainan retina di Balai Kesehatan Mata Masyarakat (BKMM) Provisi Sulawesi Utara periode Januari- Desember 2014
}

\author{
${ }^{1}$ Rohamonangan Th. Sinaga \\ ${ }^{2}$ Laya Rares \\ ${ }^{2}$ Vera Sumual
}

\author{
${ }^{1}$ Kandidat Skripsi Fakultas Kedokteran Universitas Sam Ratulangi Manado \\ ${ }^{2}$ Bagian Mata Fakultas Kedokteran Universitas Sam Ratulangi Manado \\ Email: rohamonangan_theresia@yahoo.com
}

\begin{abstract}
The prevalence of retinal abnormality in Indonesia reached $0.13 \%$ and is the fourth leading cause of blindness after cataract, glaucoma. and refractive disorders. Vitrectomy is a type of surgery to treat retinal disorders that removes the vitreous, therefore, the operation can be performed and vision can be corrected. This study aimed to determine the indications to undergo vitrectomy in retinal disorders. This was a descriptive retrospective study using data of medical records of patients with retinal disorders who underwent vitrectomy at Community Eye Health Center (CEHC) of North Sulawesi Province. There were 27 patients in this study consisted of 17 male patients (63\%) and 10 female patients (37\%). The major indications of vitrectomy were retinal detachment in 16 patients (59\%) and diabetic retinopathy in 11 patients (41\%). In case of retinal detachment male patients were the most frequent to undergo vitrectomy (12 patients; $44.44 \%$ ) than female patients (4 patients; 14.81\%). In case of diabetic retinopathy there were no difference between males (18.52\%) and females (22.22\%)
\end{abstract}

Keywords: retinal disorder, vitrectomy, retinal detachment, diabetic retinopathy

\begin{abstract}
Abstrak: Prevalensi kelainan retina di Indonesia mencapai 0,13\% dan merupakan penyebab kebutaan keempat setelah katarak, glaucoma, dan kelainan refraksi. Vitrektomi adalah salah satu jenis operasi untuk mengobati kelainan retina melalui pengangkatan vitreus sehingga retina dapat dioperasi dan penglihatan dapat diperbaiki. Penelitian ini bertujuan untuk mengetahui indikasi dilakukannya vitrektomi pada kelainan retina. Jenis penelitian ini deskriptif retrospektif dengan menggunakan data dari rekam medis penderita dengan kelainan retina yang menjalani vitrektomi di Balai Kesehatan Mata Masyarakat (BKMM) Propinsi Sulawesi Utara. Dalam penelitian ini ditemukan 27 pasien dengan kelainan retina yang menjalani vitrektomi terdiri dari 17 pasien laki-laki (63\%) dan 10 pasien perempuan (37\%). Indikasi untuk vitrektomi terbanyak pada retinal detachment sebanyak 16 pasien (59\%) dan retinopati diabetik sebanyak 11 pasien (41\%). Pada indikasi retinal detachment didapatkan pasien laki-laki yang paling banyak menjalani vitrektomi yaitu 12 pasien $(44,44 \%)$ sedangkan perempuan 4 pasien $(14,81 \%)$. Pada indikasi retinopati diabetik tidak terdapat perbedaan antara laki-laki $(18,52 \%)$ dan perempuan $(22,22 \%)$
\end{abstract}

Kata kunci: kelainan retina, vitrektomi, retinal detachment, retinopati diabetik

Retina atau selaput jala, merupakan bagian mata yang mengandung reseptor untuk menerima rangsangan cahaya. ${ }^{1}$ Retina merupakan bagian jaringan yang sangat tipis, tebalnya hampir setengah millimeter, melapisi bagian dalam bola mata. ${ }^{2}$

Prevalensi kelainan pada retina di Indonesia mencapai angka $0,13 \%$ dan 
merupakan penyebab kebutaan ke empat setelah katarak (0,78\%), glaucoma $(0,20 \%)$, kelainan refraksi $(0,14 \%)$, dan penyebab lainnya $(0,10 \%)$. Hal ini diketahui berdasarkan Survei Kesehatan Indra Penglihatan dan Pendengaran tahun $1993-1996 .^{3}$

Vitrektomi adalah operasi pengangkatan vitreus pada mata sehingga retina dapat dioperasi dan penglihatan dapat diperbaiki. ${ }^{4}$ Vitrektomi dikerjakan antara lain pada: ${ }^{5}$ ablasio retina (retinal detachment), mengkerutnya makula (macular pucker), retinopati diabetik (diabetic retinopathy), infeksi bola mata (endophthalmitis), trauma mata (benturan atau luka pada bola mata), kekeruhan vitreus, lubang makula (macular hole), dislokasi lensa intraokuler atau katarak, branch retinal vein occlusion (BRVO) atau sumbatan cabang vena sentralis retina, dan perdarahan di bawah makula retina.

\section{METODE PENELITIAN}

Jenis penelitian ini ialah deskriptif retrospektif, dengan menggunakan catatan medik pasien yang berobat ke Balai Kesehatan Mata Masyarakat (BKMM) Propinsi Sulawesi Utara selama periode Januari 2014 - Desember 2014. Subjek penelitian ialah catatan medis semua pasien dengan kelainan retina yang menjalani vitrektomi. Variabel penelitian ini ialah jenis kelamin, indikasi vitrektomi, kelainan retina yang menjalani vitrektomi.

\section{HASIL PENELITIAN}

Berdasarkan pengumpulan data yang dilakukan selama bulan November 2015 Desember 2015 secara deskriptif retrospektif di Balai Kesehatan Mata Masyarakat (BKMM) Propinsi Sulawesi Utara periode Januari 2014 - Desember 2014, didapatkan 27 pasien kelainan retina yang telah menjalani vitrektomi. Hal-hal yang diamati yaitu jenis kelamin dan indikasi vitrektomi dari penderita dengan kelainan retina yang menjalani vitrektomi.

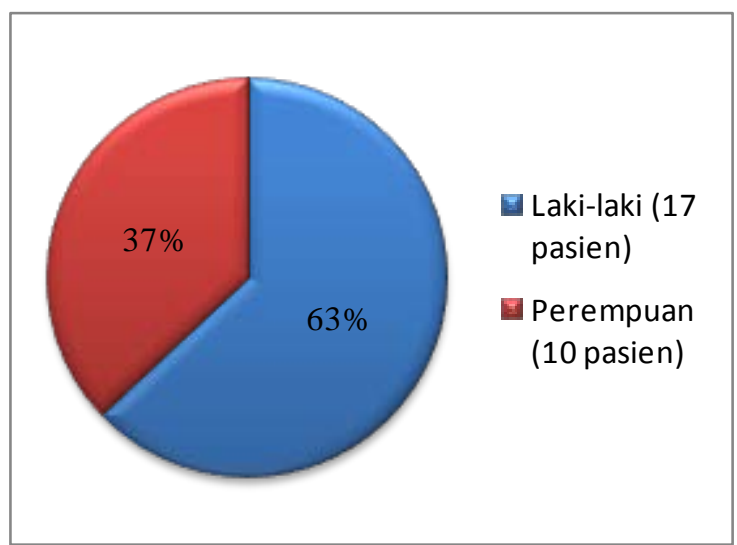

Gambar 1. Distribusi penderita kelainan retina yang telah menjalani vitrektomi berdasarkan jenis kelamin

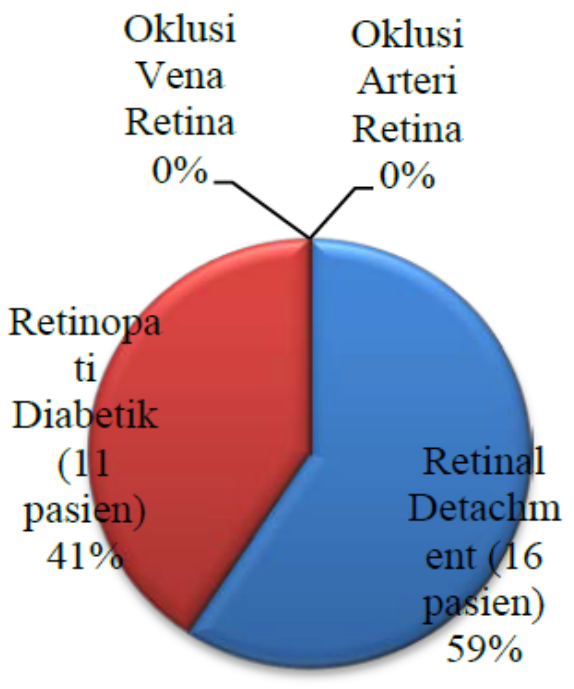

Gambar 2. Distribusi penderita kelainan retina yang telah menjalani vitrektomi berdasarkan indikasi

\section{BAHASAN}

Pada penelitian yang dilakukan di BKMM didapatkan jumlah pasien dengan jenis kelamin laki-laki (63\%) lebih banyak dari perempuan (37\%). Hal ini sejalan dengan penelitian yang dilakukan di Nepal, yang menunjukkan laki-laki lebih banyak menjalani vitrektomi dibandingkan dengan perempuan. Hal ini mungkin disebabkan populasi laki-laki lebih dominan dalam masyarakat atau kurangnya preferensi untuk kesehatan wanita. ${ }^{6,7}$ 


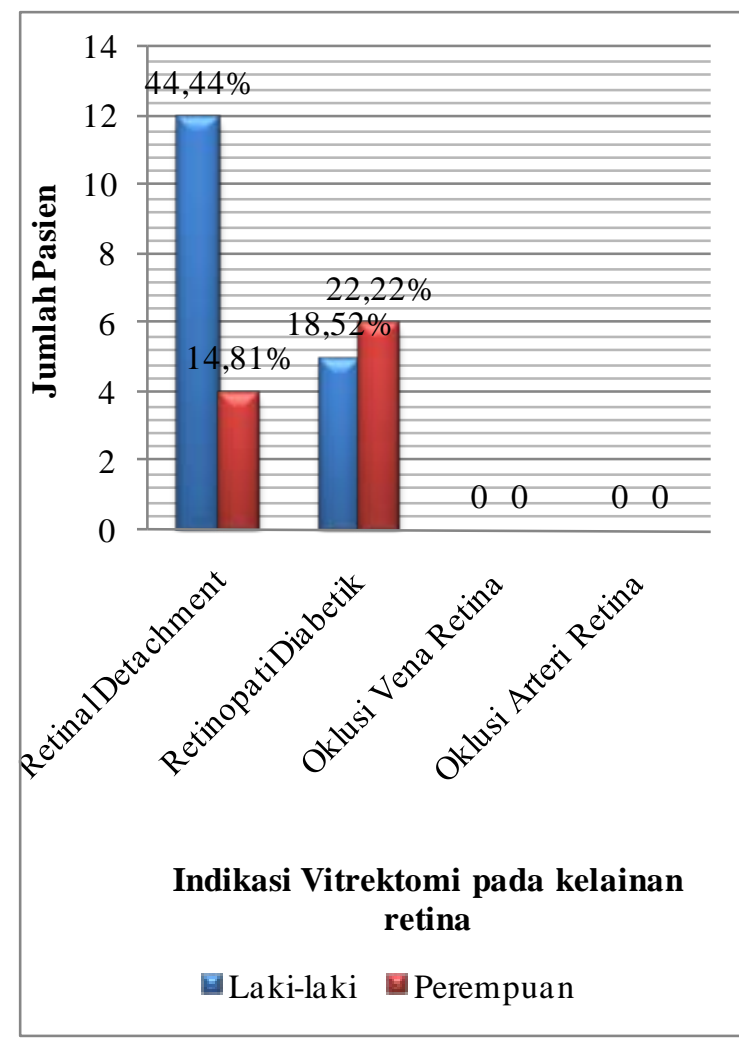

Gambar 3. Distribusi penderita kelainan retina yang telah menjalani vitrektomi dengan indikasi vitrektomi berdasarkan jenis kelamin

Berdasarkan penelitian yang dilakukan oleh Nobrega et al. ${ }^{7}$ di Brazil, indikasi vitrektomi terbanyak pada retinal detachment (46,3\%). Penelitian yang dilakukan oleh Shuahib $^{8}$ di Nigeria juga menunujukkan bahwa retinal detachment merupakan indikasi utama untuk menjalani vitrektomi (51\%). Hal serupa juga diungkapkan oleh Saxena ${ }^{9}$ bahwa saat ini retinal detachment merupakan indikasi utama dilakukannya vitrektomi.

Pada penelitian ini didapatkan indikasi yang paling sering untuk vitrektomi di Balai Kesehatan Mata Masyarakat (BKMM) propinsi Sulawesi Utara periode Januari 2014 - Desember 2014 ialah retinal detachment (59\%); hal ini sejalan dengan penelitian yang dilakukan oleh Nobreka et al di Brazil dan oleh Shuahib di Nigeria. ${ }^{7,8}$

Keuntungan utama dilakukannya vitrektomi pada retinal detachment ialah dengan vitrektomi traksi retinal detachment dapat langsung dilepaskan. Vitrektomi juga dapat menghilangkan kekeruhan pada media sehingga meningkatkan penglihatan intraoperatif dan kontrol drainase internal cairan subretina. $^{10}$

Prevalensi retinal detachment di dunia ialah 1 kasus dalam 10.000 populasi. Biasanya retinal detachment terjadi pada usia 40-70 tahun. Prevalensi meningkat pada beberapa keadaan seperti miopi tinggi, afakia/pseudofakia, dan trauma. ${ }^{11}$ Insidensi retinal detachment di Amerika Serikat berkisar antara 1 dari 15.000 populasi, dengan prevalensi $0,3 \%$ dari total populasi. ${ }^{12}$

Setelah retinal detachment indikasi terbanyak diikuti oleh penderita dengan retinopati diabetik (40,74\%). Hal ini juga serupa dengan penelitian yang dilakukan oleh Nobrega et al. ${ }^{7}$ di Brazil, dimana retinopati diabetik (22,5\%) merupakan indikasi terbanyak kedua setelah retinal detachment. Menurut penelitian yang dilakukan di Rumah Sakit Mata Cicendo Bandung, tujuan pertama dilakukannya vitrektomi pada retinopati diabetik ialah untuk memperbaiki penglihatan dan tujuan kedua ialah untuk menstabilkan proses neovaskularisasi retinopati diabetik sehingga mendapatkan hasil anatomis dan keberhasilan fungsi penglihatan jangka panjang. ${ }^{13}$

Hasil penelitian penderita kelainan retina yang menjalani vitrektomi dengan indikasi berdasarkan jenis kelamin didapatkan penderita yang menjalani vitrektomi dengan indikasi retinal detachment terbanyak pada laki-laki (44,44\%). Menurut Larkin, $\pm 60 \%$ retinal detachment ditemukan pada laki-laki. Insiden tetap lebih tinggi pada laki-laki meskipun telah dikoreksi untuk trauma okuli karena trauma okuli lebih sering terjadi pada laki-laki. ${ }^{12}$

Untuk indikasi pasien dengan retinopati diabetik tidak terdapat perbedaan yang mencolok antara laki-laki (18,52\%) dan perempuan (22,22\%). Hal ini mungkin disebabkan karena meningkatnya kesadaran akan pentingnya kesehatan, sehingga tidak ada perbedaan jumlah yang berarti.

\section{SIMPULAN}

Dari hasil penelitian tentang indikasi vitrektomi pada kelainan retina di Balai 
Kesehatan Mata Masyarakat (BKMM) Propinsi Sulawesi Utara periode Januari 2014 - Desember 2014 dapat disimpulkan sebagai berikut:

1. Tindakan vitrektomi lebih banyak dilakukan pada pasien dengan kelainan retina berjenis kelamin laki-laki.

2. Indikasi vitrektomi terdiri atas retinal detachment (yang terbanyak) dan retinopati diabetik.

3. Pada indikasi retinal detachment, jumlah pasien laki-laki yang paling banyak sedangkan pada indikasi retinopati diabetik, tidak terdapat perbedaan yang mencolok antara jumlah pasien laki-laki dan perempuan.

\section{SARAN}

1. Untuk masyarakat, agar segera melakukan pemeriksaan bila terdapat keluhan, seperti floaters (terlihat benda melayang-layang), photopsia (kilatan cahaya), kekaburan atau penglihatan berkurang secara bertahap sehingga dapat ditangani dengan cepat.

2. Untuk penderita diabetes melitus, sebaiknya rajin melakukan kontrol agar tidak timbul komplikasi.

3. Penderita dengan kelainan retina yang telah menjalani vitrektomi sebaiknya melakukan kontrol secara teratur terhadap perbaikan penglihatan.

\section{DAFTAR PUSTAKA}

1. Ilyas S, Yulianti SR. Ilmu penyakit mata (4th ed). Jakarta: Balai penerbit FKUI, 2012; p. 10

2. Kolb H. American Scientist. How the retina works. 2003. [(cited 2015 Oct 9)]. Available from: http://webvision.med. utah.edu/wp-content/uploads/2011/01/ 2003-01Kolb.pdf

3. Depkes RI, Ditjen Binkenmas, Hasil Survei Indera Penglihatan dan Pendengaran 1996,1998; p. 12-17

4. Queen Elizabeth Hospital Birmingham.
Vitrectomy Eye Surgery. 2013. [cited 2015 Oct 9]. Available from: http://www.uhb.nhs.uk/Downloads/ pdf/PiVitrectomy.pdf

5. Jakarta Eye Center. Operasi Vitreoretinal. 2009. [cited 2015 Oct 9]. Available from: http://www.oocities.org/sgtahija/operasi_ vitreoretinal.html

6. Subedi S, Sharma MK, Sharma BR, Kansakar I, Dhakwa K, Adhikari RK. Surgical outcome of pars planavitrectomy: a retrospective Study in a peripheral tertiary eye care centre in Nepal. Nepal J Ophatlmol. 2010;2(3):39-44.

7. Nobrega MJ, Casagandre C, Nunes RP, Nagel G. Indications for pars plana vitrectomy in a tertiary healthcare service in southern Brazil. Invest Ophthalmol Vis Sci. 2004;45(3):2007.

8. Shuaib A, Memon AF. Indications and visual outcome of first hundred pars plana vitrectomies at makkah specialist eye hospital, Kano, Nigeria. Nigerian J Ophtalmol. 2010;22(1):34-37.

9. Saxena S. Clinical Ophtalmology (2nd ed). India: Medical Publisher, 2010; p. 550.

10. Kwon OW, Roh MI, Song JH. Retinal detachment and proliferative vitreoretinopathy. In. Retinal Diseases Amenable to Pharmacotherapy. Britain: Saunders-Elsevier, 2010; p. 147-51.

11. National Institutes of Health. MedlinePlus Medical Encyclopedia. Retinal Detachment. 2005. Available from: http://www.nlm.nih.gov/medlineplus/ency/ article/001027.htm

12. Larkin GL. Retinal detachment. Medscape. Available from: http://emedicine.medscape.com/article. 798501-overview

13. Sovani I. FK UNPAD. Indikasi vitrektomi pada retinopati diabetika. 2000. [cited 2015 Dec 27]. Available from: http: //pustaka.unpad.ac.id/wp-content/ uploads/2009/07/indikasi_vitrektomi_p ada_retinopati_diabetika.pdf. 